\title{
ICT as a tool to form the readiness of future teachers to work with left-handed education applicants
}

\author{
Hanna Ihnatenko ${ }^{1, *}$, Inna Marynchenko, ${ }^{1, * *}$, Oleksandr Ihnatenko ${ }^{1, * * *}$, Eugene Marynchenko, ${ }^{1, * * *}$, and Albina \\ Zinchenko ${ }^{1, \dagger}$ \\ ${ }^{1}$ Oleksandr Dovzhenko Hlukhiv National Pedagogical University, 24 Kyevo-Moskovska Str., 41400, Hlukhiv, Ukraine
}

\begin{abstract}
The article points out that currently in Ukraine the increasing attention is directed to the definition of ICT, providing the maximum consideration of individual peculiarities of education applicants. The approaches to the definition of left-handed education applicant (left hand is the leading one) and the notion of ambidextrous (the ability of a person to use both hands equally) are identified. In order to determine the readiness of future teachers to work with left-handed education applicants, a survey of second- and third-year students at Oleksandr Dovzhenko Hlukhiv National Pedagogical University was conducted. It was determined that the vast majority (over 80\%) among them have limited understanding of the peculiarities of teaching left-handed people. It is proved that there is an urgent need for specialists with appropriate theoretical and practical training, who are capable of effectively teaching left-handed pupils in accordance with their individual-psychological features. The level of empathy found in future educators indicates a positive psychological state of the vast majority of students, which will enable them to form inclusive competence more effectively. It is determined that the "mirror reflection method" is scientifically and methodologically justified to work with left-handed education applicants. In order to prepare future educators to work with left-handed education applicants, online software for mirroring photo and video materials has been identified.
\end{abstract}

\section{Introduction}

Reforming higher education in Ukraine, moving to a new person-centred approach in training and education is impossible without creating the necessary conditions to ensure sustainable development of the teacher himself $[1,2]$.

Information and communication technologies (ICT) are significant drivers of the globalization of society. When it comes to inclusion in education, they can help education applicants with special needs to realise their right to study, fulfil their potential and socialise in society [3] and [4].

The UNESCO prohibit any exclusion from, or limitation to, educational opportunities on the basis of sociallyascribed or perceived differences, such as by sex, ethnic/social origin, language, religion, nationality, economic condition, ability. Reaching excluded and marginalized groups and providing them with quality education requires the development and implementation of inclusive policies and programmes. In this context, UNESCO promotes inclusive education systems that remove the barriers limiting the participation and achievement of all learners, respect diverse needs, abilities and characteristics and that eliminate all forms of discrimination in the learning environment [5].

\footnotetext{
*e-mail: dekdzn@gmail.com

**e-mail: inna_sheludko@ukr.net

***e-mail: sashagid@gmail.com

****e-mail: marinchenko1993@ukr.net

†e-mail: Zin_A@i.ua
}

According to the Centre for Public Monitoring and Control, among 1,337 Ukrainian schools, only 1,127 are adapted to the needs of inclusion in education. More than 56,000 schoolchildren, future professional education applicants with disabilities, are not enrolled at all in general education institutions. Therefore, only significant changes in the structure of the national education system towards inclusion in education will make it possible to form a qualitatively new mechanism of interaction between pedagogical institutions to ensure the socialization of each student [6].

The solution of the problem of inclusion in education is mutually conditioned by taking into account the individual characteristics of students: peculiarities of perception of the world, thinking, memory, imagination, interests, aptitudes, etc., that is all that largely predetermines the process of mastering knowledge, practical skills, formation of personal qualities and professional abilities.

Nowadays in Ukraine more and more attention is directed to the identification of ICT, which ensures maximum consideration of individual features of education applicants.

Training and education of left-handed students has been studied in a number of studies [7-22].

M. Annett's research points out that cultural and biological factors interplay in determining the leading hand [23]. M. Annett emphasizes the contradictory nature of theories and research in this field. 
Even at the early stages of mental development of right- and left-handed children, differences related to the peculiarities of functional specialization of the brain hemispheres are noticeable.

The problem of the development of emotionalvolitional and motivational spheres of personality is covered in a number of scientific works, where the connection of indicators of asymmetry of the human brain with its individual-psychological peculiarities is established.

In particular, the functional asymmetry of the brain was studied in [24-43]. Scientific research shows that the functional asymmetry of the brain has a significant impact on the formation of mechanisms of perception and learning.

Scientists believe that a teacher must have knowledge about the types of functional asymmetry of the brain, must be able to identify the individual profile of the lateral organization of the brain, as the educational technology of the third millennium must be built with due regard for the individual characteristics of a child.

The above-mentioned aspects of future teachers' training refer to the concept of "inclusive competence". The stages and features of inclusive competence formation of future teachers are considered in [44-63].

Analysis of literature on the problems of ICT application in inclusion in education has revealed that this issue, with a focus on pre-school education, is being addressed by T. Kramarenko, K. Bondar and O. Shestopalova [64], O. Kovshar, M. Baditsa and K. Suiatynova [65], M. Marienko, Z. Matyukh, Y. Nosenko, V. Osadchyi, M. Shyshkina, H. Varina and others studies general aspects of ICT integration in inclusion in education [66-68].

However, at the present time a contradiction is traced between the importance and necessity of taking into account individual characteristics of pupils, and the lack of skills for this among a significant number of teachers, which requires changes in the process of methodological training of future teachers.

The outlined concerns also the problem of creating comfortable learning conditions in educational environments for left-handed education applicants.

\section{Results and discussion}

We consider that the readiness to work with left-handed applicants for education is a part of inclusive competence of future teachers.

Our study aims to consider ICT as a tool for developing readiness of future teachers of professional education to work with left-handed education applicants. We proceed from the fact that left-handedness is one of the variants of normal body development, not too common and habitual, but having the right to exist.

Let us note that the phenomenon of ambidextrous (from Latin Ambi, "both" and Latin Dexter, "right") becomes important in the study as well - it is the ability of a person to equally master both hands. There are about $4.7 \%$ of people in the world who are proficient with both hands.
Another widely accepted concept is that of partial dominance of the hemispheres of the human brain, which was formed by R. Sperry (winner of the Nobel Prize in Physiology and Medicine, 1981). According to it, each hemisphere is in a certain way dominant in "its" function of providing cognitive processes.

The work of the brain, with simultaneous work of both the left and the right hemisphere, allows a person to increase the memory capacity, speed and quality of perception and information processing. One of the areas where the phenomenon of ambidexterity is most evident is human learning activity [69].

In order to determine the readiness of potential educators to work with left-handed education applicants we have conducted a survey of future teachers of the second-third year of study at Oleksandr Dovzhenko Hlukhiv National Pedagogical University (the sample is about 300 people).

It was discovered that education applicants are mostly familiar with the diagnostic tools to identify the leading hand in those who learn. We found out about the difficulties that the respondents experienced during their pedagogical practice with left-handed students by analyzing the answers to the question: "What are the difficulties in teaching left-handed education applicants?".

Predominantly among the difficulties the future teachers mentioned the problem of perceiving the demonstration of techniques for performing certain actions or operations.

In order to find out in more detail what students know about the problem of left-handedness and what they see as its essence, an open-ended question was asked: "What is your understanding of the essence of left-handedness?" It is worth noting that a significant number of respondents (about 33.5\%) cannot explain its essence. Having worked through the questionnaire we received the following information: $27.2 \%$ of the students answered the question "What is your understanding of the essence and content of the concept 'ambidextrous'?" while $19.1 \%$ abstained from answering. 53.7\% interpreted the above definition as "equal possession of both right and left hand by a man". To the question: "Are there any peculiarities in the organization of the educational process for left-handed students?" a small number of respondents pointed out that on this question they lack knowledge; $62.7 \%$ pointed out the peculiarities of demonstrating certain operations; $25.4 \%$ pointed out the need for an individual approach to lefthanded applicants for education.

To the question "Do you know the method of mirroring in the teaching of left-handed education applicants? Do you have the technology to apply it in practice?" $85 \%$ of respondents answered yes, but only $30 \%$ had clear guidelines on how to apply it in practice.

Answering the question: "What difficulties can a teacher experience in teaching left-handed applicants for education?" 44.9\% mentioned "left-handed people's slowness in performing their tasks", "imperfect spatial orientation", "poor handwriting"; $20.6 \%$ - distortion of shapes and proportions of figures during their graphic representation; 9.4\% - mirror reading and writing; $25.1 \%$ - difficulties in how to help right-handed teachers with left- 
handed education applicants, in particular when they write and perform work activities with their left hand and vice versa with left-handed teachers with right-handed education applicants.

On the basis of the mentioned above it is possible to assert that the majority of applicants for professional education are aware of the necessity of an individual approach to left-handed pupils.

The results of the diagnostics of the applicants' practical readiness to work with left-handed students have shown that only a small number of respondents $(20.6 \%)$ are actually prepared.

Based on the conducted research, it can be stated that there is an urgent need for specialists with appropriate theoretical and practical training, able to effectively teach left-handed pupils in accordance with their individualpsychological features.

Thus, at the initial stage of the research it was determined that the vast majority (more than $80 \%$ ) of future teachers have limited understanding of the peculiarities of teaching left-handed learners. However, they understand that it is necessary to obtain special professional knowledge in this direction, as they have had experience in communicating or working with left-handed children. The level of empathy found in future teachers allows us to state a positive psychological state of the vast majority of students, which would enable them to more effectively form their inclusive competence.

In pedagogical practice, there is a close relationship between visual and verbal methods. It has been scientifically proven that perception through the first signal system is organically combined with the functioning of the second signal system. However, it is necessary to provide a difference in the methods of using visualization for left-handed and right-handed applicants of education, taking into account that they are in a single educational environment.

In our study we adhere to the opinion of Y. Nosenko [70], who distinguishes three main ways of using ICT in inclusion in education: for compensatory purposes; for communicative purposes and for didactic purposes. During the studies of left-handed learners ICT contribute to differentiation, satisfaction of individual needs, personal development with full inclusion in the educational environment. After all, for left-handed people, the issues of training spatial perception and visual memory are especially relevant.

Scientifically and methodologically proven to work with left-handed education applicants is the "mirror reflection method". In the mirror, the demonstration of work actions is reflected as if inside out. The left hand is the right hand and the right hand is the left hand. In order to introduce this method into the educational process, the teacher must first prepare students for the mirror perception of the work actions in the process of individual work with them. But the quality of the educational process depends on the teacher's ability to divide the labor activities into separate steps, which are to be mastered step by step [71]. These are rather complex, time-consuming processes.

In order to train future teachers to work with lefthanded education applicants we have designed training methods using online software for mirror processing of photo and video materials.

IM2GO is a free online graphics editor (https://www. img2go.com/). This service has a wide range of features. It allows you to do many operations with images. You can resize, compress, rotate, mirror, add text and stickers, and apply various graphics filters.

To resize an image you need to upload it by pressing the 'Select File' button and after the image has been uploaded set the required settings.

1. You need the graphic file format.

The most commonly used file format for images is JPG, which gives acceptable image quality with sufficient compression. To select the JPG format, click on the drop down list.

\section{Resize.}

This setting allows you to select the desired dimensions for the image. Note that the service supports proportional resizing. In other words, it is enough to specify one of the required parameters (length or width) and the image will be resized proportionally.

3. Select resolution (number of dots per square inch).

A pixel is a dot in a digital image. Everything we see on a monitor screen or digital camera display is made up of pixels. When referring to digital image resolution or digital image size, it means the number of pixels in the length and height of the image. After selecting the settings, press the start button. A page will open on which you can download the resulting image.

In photography, image mirroring is the process of creating an inverse copy of an image in either the vertical or horizontal axis. Displaying the image horizontally will create a mirror image, while displaying the image vertically will look like reflecting an object in water. The image mapping retains the quality of the original image because the internal pixel information is not changed, except for the pixel order (figure 1).

Thus, an image where certain diagrams are made by a right-handed teacher due to mirroring will be understood by left-handed students.

Clideo (https://clideo.com/) is an online video formatting program that works with all popular formats like AVI, MP4, VOB, MPG, MOV and more. The app is specially designed for video reflection, so its interface is intuitive and easy to use. You can use the application not only to change the orientation of the video clip but also as a converter to change its format. Using Clineo's settings, you can quickly create YouTube, Facebook, Instagram and Instagram Story videos (figure 2).

Scientists argue that in order to increase the effectiveness of teaching left-handed people, it is necessary to use the capabilities of the right hemisphere as often as possible to make full use of its inherent features: greater speed and emotionality of perception, generalization, integrity, imagery, involvement of involuntary memory. For this purpose it is useful to systematically include manipulations 


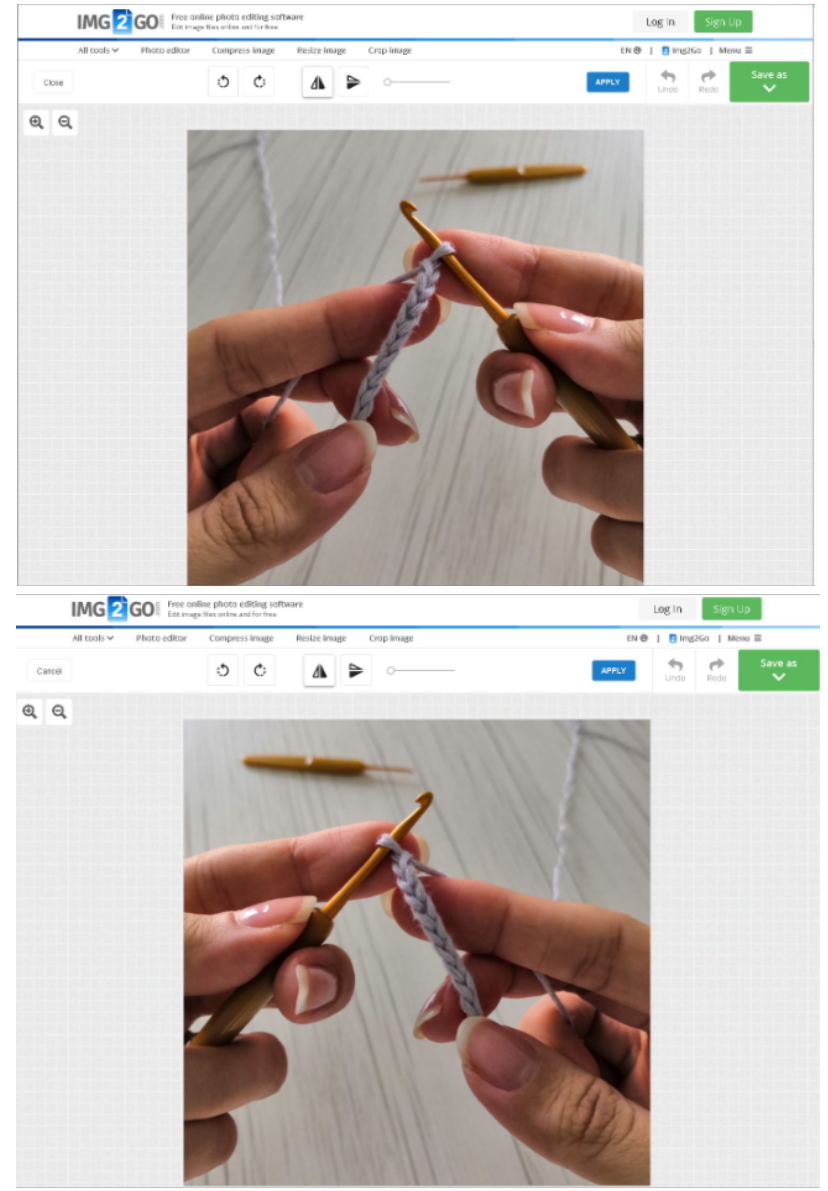

Figure 1. Example of IM2GO operation: image mirroring

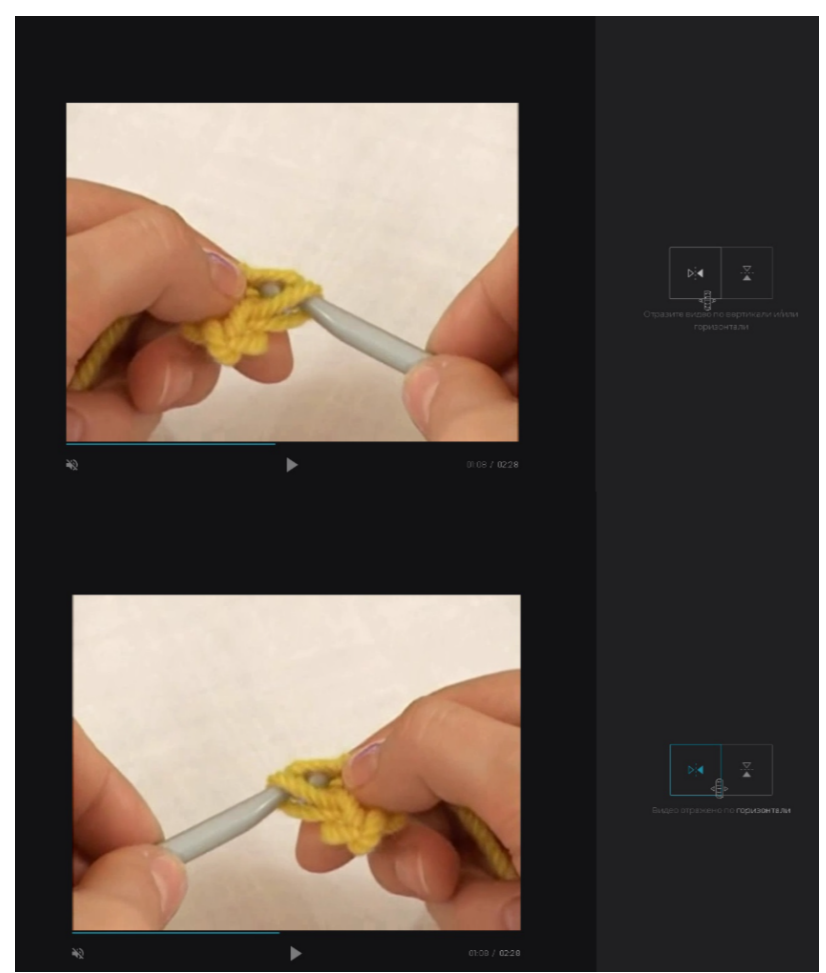

Figure 2. An example of the Clideo workflow: video mirroring with models and models in the educational process. It is possible to activate the capabilities of the right hemisphere by skillfully using all kinds of schemes.

Therefore, in our study the software interface was used as an ICT tool for future teachers to assimilate ways of working with left-handed education applicants. The results of the pedagogical experiment showed the effectiveness of the proposed approach.

\section{Conclusions}

The ICT play an important role in addressing the priority tasks of accessibility of training, education and development of education applicants with special needs. Its use as a technical aid, in particular for didactic purposes, contributes to the effective presentation of visibility for lefthanded applicants for education, it also increases their motivation to learn subjects, widens the scope of their independent activity and improves their self-esteem.

Further directions of our research are related to the development of methods for the introduction of ICT in the work with left-handed education applicants at the stage of professional (vocational) education.

\section{References}

[1] E. Komarova, T. Starova, E3S Web of Conferences 166 (2020)

[2] O. Lavrentieva, V. Pererva, O. Krupskyi, I. Britchenko, S. Shabanov, E3S Web of Conferences 166 (2020)

[3] M. Turner-Cmuchal, S. Aitken, in Implementing Inclusive Education: Issues in Bridging the PolicyPractice Gap (Emerald Group Publishing Limited, 2016), Vol. 8 of International Perspectives on Inclusive Education, pp. 159-180, ISBN 978-1-78635388-7

[4] C.N. Greene, Design Guidelines for Developing Curriculum-Focused ICT Materials for Diverse Students, in Computers Helping People with Special Needs, edited by K. Miesenberger, J. Klaus, W. Zagler, A. Karshmer (Springer Berlin Heidelberg, Berlin, Heidelberg, 2010), pp. 495-502, ISBN 9783-642-14097-6

[5] UNESCO, Inclusion in education (2021), https://en. unesco.org/themes/ inclusion-in-education

[6] T.V. Bondarenko, Information Technologies and Learning Tools 67, 31 (2018)

[7] M. Peters, Neuropsychologia 24, 429 (1986)

[8] B. Spiegler, G. Yeni-Komshian, Neuropsychologia 21, 651 (1983)

[9] J. Bradshaw, N. Nettleton, L. Wilson, C. Bradshaw, Brain and Cognition 6, 377 (1987)

[10] J. Obrzut, P. Conrad, M. Bryden, C. Boliek, Neuropsychologia 26, 119 (1988)

[11] E. Hoffmann, W. Chang, K. Yim, Applied Ergonomics 28, 245 (1997) 
[12] M. Fearing, C. Browning, D. Corey, A. Foundas, Perceptual and Motor Skills 92, 323 (2001)

[13] A. Delisle, D. Imbeau, B. Santos, A. Plamondon, Y. Montpetit, Applied Ergonomics 35, 21 (2004)

[14] M. Kaya, R. Orbak, International Journal of Industrial Ergonomics 33, 387 (2004)

[15] K. Inkpen, D. Dearman, R. Argue, M. Comeau, C.L. Fu, S. Kolli, J. Moses, N. Pilon, J. Wallace, International Journal of Human-Computer Interaction 21, 91 (2006)

[16] C. Faurie, N. Vianey-Liaud, M. Raymond, Laterality 11, 57 (2006)

[17] J. Donnot, Laterality 12, 216 (2007)

[18] A. Mehrdad, M. Ahghar, Learning styles and learning strategies of left-handed EFL students (Istanbul, 2012), Vol. 31, pp. 536-545, ISSN 18770428

[19] S. Al-Johany, Journal of Dental Education 77, 105 (2013)

[20] R. Hawkyard, I. Dempsey, M. Arthur-Kelly, Australian Journal of Education 58, 123 (2014)

[21] S. Alnassar, A. Alrashoudi, M. Alaqeel, H. Alotaibi, A. Alkahel, W. Hajjar, G. Al-shaikh, A. Alsaif, S. Haque, S. Meo, BMC Medical Education 16 (2016)

[22] I. Al Lawati, H. Al Maskari, S. Ma, European Journal of Dental Education 23, 316 (2019)

[23] M. Annett, Perceptual and Motor Skills 82, 115 (1996)

[24] P. Bakan, Perceptual and motor skills 28, 927 (1969)

[25] R. Gur, R. Gur, B. Marshalek, Journal of Educational Psychology 67, 151 (1975)

[26] S. Berent, Neuropsychologia 15, 829 (1977)

[27] J. McGlone, Cortex 14, 122 (1978)

[28] G. Stein, R. Gibbons, M. Meldman, Cortex 16, 223 (1980)

[29] T. Chernigovskaya, L. Balonov, V. Deglin, Brain and Language 20, 195 (1983)

[30] T. Chernigovskaya, V. Deglin, Brain and Language 29, 141 (1986)

[31] C. dos Santos, J.L. Nespoulous, P. Celsis, G. Viallard, Journal of Neurolinguistics 6, 285 (1991)

[32] P. Nikolova, Z. Stoyanov, N. Negrev, International Journal of Psychophysiology 18, 213 (1994)

[33] M. Koivisto, Brain and Cognition 29, 36 (1995)

[34] M. Koivisto, Cortex 32, 527 (1996)

[35] A. Nowicka, A. Grabowska, E. Fersten, Neuropsychologia 34, 147 (1996)

[36] H. Karbe, K. Herholz, G. Weber-Luxenburger, M. Ghaemi, W.D. Heiss, Brain and Language 63, 108 (1998)

[37] G. Brown, M. Caligiuri, M. Meloy, S. Eberson, S. Kindermann, L. Frank, L. Zorrilla, J. Lohr, Journal of Clinical and Experimental Neuropsychology 26, 356 (2004)

[38] E. Udachina, Psikhologicheskii Zhurnal 22, 64 (2001)
[39] I. Asenova, Voprosy Psikhologii pp. 100-110+160 (2005)

[40] A. Nowicka, P. Tacikowski, Laterality 16, 35 (2011)

[41] N. Khokhlov, M. Kovyazina, Acta Neuropsychologica 11, 269 (2013)

[42] L. Van der Haegen, R. Westerhausen, K. Hugdahl, M. Brysbaert, Neuropsychologia 51, 91 (2013)

[43] V. Rangarajan, J. Parvizi, Neuropsychologia 83, 29 (2016)

[44] C. Everington, B. Stevens, V. Winters, Psychological Reports 85, 331 (1999)

[45] M. Fisher, L. Meyer, Research and Practice for Persons with Severe Disabilities 27, 165 (2002)

[46] A. Moran, International Journal of Inclusive Education 13, 45 (2009)

[47] J. Batanero, Revista Electronica de Investigacion Educativa 15, 82 (2013)

[48] L. Milteniene, S. Daniute, Specialusis Ugdymas 30, 27 (2014)

[49] G. Mu, Y. Wang, Z. Wang, Y. Feng, M. Deng, S. Liang, International Journal of Disability, Development and Education 62, 571 (2015)

[50] Z. Nigmatov, A. Huziakhmetov, Social Sciences (Pakistan) 10, 620 (2015)

[51] E. Ketrish, E. Dorozhkin, O. Permyakov, N. Tretyakova, T. Andryukhina, V. Mantulenko, International Journal of Environmental and Science Education 11, 8237 (2016)

[52] E. Kirillova, G. Ibragimov, Journal of Organizational Culture, Communications and Conflict 20, 180 (2016)

[53] S. Navarro, P. Zervas, R. Gesa, D. Sampson, Educational Technology and Society 19, 17 (2016)

[54] J. del Castillo-Olivares Barberan, O. Alegre de la Rosa, E. Torres, The video workshop as a strategy for development of inclusive competences (Nova Science Publishers, Inc., 2017), ISBN 9781536109016; 9781536108842

[55] Z. Ke, N. Borakova, G. Valiullina, Eurasia Journal of Mathematics, Science and Technology Education 13, 4701 (2017)

[56] T. Kenzhebayeva, M. Zhakupov, L. Reznik, A. Ayapbergenova, A. Akhmetova, D. Zhakupova, Man in India 97, 219 (2017)

[57] V. Kiswarday, T. Stemberger, Didactica Slovenica Pedagoska Obzorja 32, 3 (2017)

[58] C. Blume, D. Gerlach, B. Roters, T. Schmidt, TESLEJ 22 (2019)

[59] I. Emelyanova, S. Markova, O. Podolskaya, Perspektivy Nauki i Obrazovania 40, 361 (2019)

[60] G. Albeanu, M. Andronie, Proform-best practices in professional and transversal competences development for teaching in inclusive schools (National Defence University - Carol I Printing House, 2020), pp. 419-428, ISSN 2066026X

[61] M. Brcic, R. Petani, M. Miocic, Sodobna Pedagogika/Journal of Contemporary Educational Studies 71, 156 (2020) 
[62] M. Fidarova, S. Alvorova, E. Ivankova, Perspektivy Nauki i Obrazovania 43, 163 (2020)

[63] M. Tilve, M. Mendez, Revista de Investigacion Educativa 38, 239 (2020)

[64] T. Kramarenko, K. Bondar, O. Shestopalova, Journal of Physics: Conference Series 1840, 012009 (2021)

[65] O. Kovshar, M. Baditsa, K. Suiatynova, International Journal of Engineering and Advanced Technology 9 , 4556 (2019)

[66] Y. Nosenko, Z. Matyukh, CEUR Workshop Proceedings 1844, 459 (2017)
[67] M. Marienko, Y. Nosenko, M. Shyshkina, CEUR Workshop Proceedings 2731, 341 (2020)

[68] V. Osadchyi, H. Varina, K. Osadcha, O. Prokofieva, O. Kovalova, A. Kiv, CEUR Workshop Proceedings 2731, 263 (2020)

[69] K. Rosing, M. Frese, A. Bausch, Leadership Quarterly 22, 956 (2011)

[70] Y.H. Nosenko, Z.V. Matiuh, Information Technologies and Learning Tools 57, 1 (2017)

[71] H. Ihnatenko, O. Ignatenko, Journal L'Association 1901 "SEPIKE" pp. 28-32 (2015) 